\title{
Fighting Social Normalisation in Generation Z: Trans* Youth
} Activism on Tumblr

\author{
Joshua Harris
}

\begin{abstract}
Activism for socio-political movements has been affected by the progression of technology, enhancing the conditions under which advocates can communicate worldwide. Recently, Tumblr has announced accommodating large numbers of young transgender identified individuals. This article will offer an historical analysis of the progression of gay rights throughout the twentieth century, in comparison with the similar trajectory of the transgender movement now being catalysed by technology. Through discussing key arguments in transgender theory such as the pathologisation of Gender Dysphoria in the DSM; the heterogeneity of the transgender community; and rejecting essentialist ideas of gender: we can begin to understand the need for further integration of the rhetoric of gender fluidity into the public space, in which wrong body discourse and the politics of passing can be deconstructed. By dissecting the history of mainstream media representation of gay identities, we can now understand them to be in the final 'respect' stage, progressing through 'non-recognition', 'ridicule', and 'regulation' (Clark, 1969). A further comparison with transgender representation will highlight a non-recognition of the full heterogeneity of their community, which exemplifies the need for public discussion. Tumblr has a unique opportunity, as the biggest cyberspace community of young transgender identified individuals, to impact dialogues created around transgender politics. A discourse analysis of Tumblr's platform evidences a need to optimise its usability for transgender members. The arguments will conclude proposing that Tumblr has the ability to create a space for influential dialogues that could expand past Tumblr and into wider public spaces.
\end{abstract}

Keywords: Transgender, Gender politics, Tumblr, Social network, Media representation, normalisation, generation $\mathrm{Z}$, activism

\section{Introduction}

Activism strategies for socio-political movements have developed exponentially over the 20th and 21st century. The progression of technology has consolidated the way that advocates communicate worldwide and, through these expansive communicative strategies, wider political narratives have nuanced into smaller groups finding specificity within their wider politics. This paper specifically analyses how transgender politics exemplify the progression of activism into generation $Z$ : a demographic collective made up of individuals born since the mid 1990's who are considered confident using technology. It will analyse the impact the internet has had on mobilising transgender politics, the current 
state(s) of these politics, and hypothesise what can be done to further transgender political dialogues in public spaces, specifically starting from Tumblr.

A regimented gender binary exists in western culture and to fully understand the transgression of gender occurring increasingly prevalently in present society, it is important to be familiar with arguments that Judith Butler has put forward in Gender Trouble (1990). Gender is independent of sex, and "whatever biological intractability sex appears to have, gender is culturally constructed" (Butler, 1990)(6). Butler argues that 'the body' exists as a canvas on which cultural meanings are etched or interpreted by the subject, which in turn creates "a cultural meaning for itself" (8). Importantly, Butler states: "There is no gender identity behind the expressions of gender; that identity is performatively constituted by the very 'expressions' that are said to be its results." (25) Historically in western culture, gender has been culturally constructed to be binary, but with the progression away from conservative notions of sexuality, to be explained using Foucault's arguments, there is a need for a development in the wider understanding of gender transgression. An understanding which should be considered with Butler's 'gender as performative' ideas at its base.

Firstly by explaining what this paper terms as 'normalisation', as Foucault outlines in Discipline and Punish (1977) using an example within the prison system, one can begin to understand the power relations involved in the repression of 'undesirable' characteristics. For idealised standards of conduct to be exemplified on a mass scale, a reward and punishment system must be in place, enforced by a 'power', that takes effect on individuals whom conform to, or deviate from, these idealised standards of conduct. Although this metaphor does act as an effective image to consider the reward and punishment system, the context of this essay does not lie within the prison system, but will examine the relationships of power involved in the repression of gender play. For the purposes of this essay, 'social normalisation' of gender, then, accounts for the reward and punishment system favouring binary notions of gender, that influences the socialisation of the population in western civilisation.

Foucault (1978) found that the repression of sexuality was etched in history, and because of it being "so firmly anchored, having solid roots and reasons" (9), it is very difficult to 
dismantle. Foucault (1978) states that "power is essentially what dictates its law to sex", and it is placed in "a binary system: licit and illicit" (83). Historically, the 'power' of which Foucault speaks of manifests itself in different terminal forms that can act simultaneously or independently from one another (92). Between the 1700s and the victorian era, Foucault found that, a rhetoric of purely 'reproductive' sexuality was being used by the church, that frowned upon any sexuality that wasn't procreative. He termed this "a socialisation of procreative behaviour" and defines this as: "an economic socialisation via all the incitements and restrictions, the 'social' and fiscal measures brought to bear on the fertility of couples; a political socialisation achieved through the 'responsibilization' of couples with regard to the social body as whole, and a medical socialisation carried out by attributing a pathogenic value to birth control practices" (Foucault, 1978)(104).

This 'socialisation of procreative behaviour' is still explicit when considering the repression of gender transgression today; unfortunately, in the western world, we are still experiencing homophobia and transphobia as a result of these conservative ideas of sexuality and gender being etched in history. When discussing the 'deployment of sexuality' on children, which Foucault (1978) suggested was forced on the 'home' (family) to provide, he cited that it drew on outside support from the church, government, medicine and psychiatry; 'powers' that all appeared to be experts in the field of sexuality (110).

The rhetoric that these 'experts' presented resulted in 'illicit', non-procreative sexuality being lumped together autonomously with adultery and rape (Foucault, 1978) (39); and further, these 'illicit' activities were then used as evidence for the psychiatrisation of the subject, it was a choice between "normalisation or pathologisation" (105). As a result, presently for the transgender community who are seeking sex reassignment, it is stay as your birth sex or face pathologisation; and further, if the individual completes sex reassignment, it is 'pass' (become a normalised vision of gender) or face transphobic hate. It is evident from Foucault's examination of power relationships, that specific discursive networks are functioning in what he terms 'normalisation'. Building on this, ideas of normality and abnormality can then be considered to be operationalised.

Engaging specifically with transgender, one should understand that a cis-normative mindset is currently upheld worldwide. This revolves around a binary system that only 
validates essentialist forms of gender (i.e. male / female). As a result, this 'social normalisation' of transgender representation has developed around the idea of 'passing': making yourself 'look like' a boy or a girl, which has resulted in much of the transgender population representing themselves as hyper-feminine or hyper-masculine. However, there are individuals that deviate away from these essentialist ideas of gender, on a gender fluid spectrum, that challenge the frameworks upheld by current 'power' in western society that define what is considered 'normal' and 'abnormal'. Recognising progressive transgender theory is important to discern where activists' ideologies lie. This writing will consider terms associated with, and defining, groups considered under the umbrella term 'transgender', specifically the emergence of 'trans"' or

'trans snowflake' online. It will further dissect key issues in gender fluid politics such as the importance of deconstructing wrong body discourse (WBD), and depathologising Gender Dysphoria (GD).

To understand the progression of socio-political activism into the 21st century it is important to highlight similar advocacy during the 20th century. This writing will reflect on movements that maintained the advancement of gay rights and comparatively look at transgender activism, prior to and following the birth of the internet; highlight problems that it will face; and outline how Transnational Advocacy Networks (TANs) will develop a larger and more nuanced conversation about transgender (Ciszek, 2017). Popular culture, specifically tv and film representation, has created cultural artefacts that realise a popular understanding of gender and sexuality (Benshoff and Griffin, 2006). Using Clark's hypothesis (1969) on the four chronological stages of media representation of minority social groups, one can identify the impact of gay rights activism on popular culture resulting in gay representation entering the final 'respect' stage. Comparatively, one can identify transgender identities in tv and film and hypothesise, with the correct activism, the future of transgender representation in popular culture; and further what this advocation would do for the trans-liberation movement.

By establishing the importance of the internet on transgender politics it is vital to expand on differing online transgender perspectives and communities. Most notably Raun's (2012) writing on YouTube and Drager's (2012) writing on Tumblr have highlighted the differing 
transgender communities thriving on their respected platform; and have offered insight into how the different platforms cater for their own particular transgender community. With specific interest in Tumblr, this essay will dissect its platform as a way to create and discuss coherent gender fluid narratives as a form of activism; as well as critique its tag based system and offer a hypothesis on how to improve the platform for the benefit of transgender activism. Through this critique of its platform, one can then move into a critical discourse of the present state of transgender politics, comparing the current mainstream media tropes with the heterogeneity of Tumblr's transgender population. Thus, warranting a change in film/tv mindset about transgender narratives. Further, it will suggest how a wider public space discussion of transgender, starting on Tumblr, could have a massive impact on the way that the public considers fluidity of gender and resultantly how this public realisation will fight current frameworks in place that affirm social normalisation of gender to a binary.

\section{Comparative Critical Cultural Responses to Gay Rights and Transgender Politics}

\section{Transgender Terminology}

'Transgender' has generally been understood as an umbrella term to encompass any gender bending individual that doesn't conform to hegemonic regimes of gender. A 'Transexual' is defined, as such, by taking a surgical discourse (sex re-assignment specifically) in the context of their gender non-conformity (Richardson, 2010). Due to a fetishisation of '\#transgender', to be explained later, '\#trans"' has now been adopted by users on Tumblr as an umbrella term to encompass "Transgender, Transsexual, genderqueer, Non-Binary, Genderfluid, Genderfuck, Intersex, Third gender, Transvestite, Cross-dresser, Bi-gender, Trans man, Trans woman, Agender" (Joey and Kaiden, 2011). The * or 'snowflake' is used to distinguish itself away from '\#trans' which is understood to solely carry transition blogs relating to the process of transitioning through a medical discourse (hormones and surgery) (Drager, 2012). Fink and Miller (2014) claim that the label 'trans"' or 'trans snowflake' is a more politically active tag than that of '\#trans'. In attempt to find a particularity, this essay will use the term 'transgender' as Richardson has 
outlined to discuss the history and arguments associated with the group. With subsequent explanation to follow, this writing will discourse trans* as an online community and political rhetorics stemming from it (Hines, 2006).

\section{Gay Rights Activism}

In order to analyse how generation $Z$ is affecting socio-political movements, specifically transgender, this essay will chronologically work through the history of gay rights initiatives in the western world. In 1897 the Scientific-Humanitarian Committee in Berlin began the advancement of the citizenship rights of gay and lesbian individuals. However, the authoritarian politics of sexual regulation that emerged halted gay rights activism, and it wasn't until the end of both world wars that new movements initiated (Adam, Duyvendak and Krouwel, 1999). In the US, it was the 1950's post-war urbanisation of growing cities that offered 'new havens' for homosexuals. It was this that enabled them to find one another in public areas and congregate in bars and other social spaces that led to the rise of the 'Homophile' movement (Epstein, 1999).

An influential transformation arrived in the form of the New Left during the 1960's and 1970's that catalysed civil rights movements all over the western world (Adam, Duyvendak and Krouwel, 1999), spawning localised student movements in North America, Western Europe, Japan, Mexico and Czechoslovakia (Wallerstein, 1989). With this rise in activism also arrived the self identifying terms 'gay' and 'lesbian' which overshadowed the pathologised 'homosexual' (Benshoff and Griffin, 2006). Sexual repression and gender advocacy then further nuanced into the 'Gay Liberation' and 'Lesbian Feminist' movements beginning in the late 1960's and through the 1970's (Adam, Duyvendak and Krouwel, 1999).

As a result of the mass following and cultural impact that these movements were creating, progressive political rhetoric became popularised, for instance the birth of the term 'Homophobia' (Weinberg, 1972). The oppressive force connoted by 'homophobia' directly relates to homosexual individuals: it is the dislike of, or prejudice towards, homosexual individuals exclusively. This was a progressive step forward in comparison to the term 
racism (c. 1935) that connotes that any race, oppressed or not, could be victimised; and sexism (c. 1965), in the same way, connotes that both sexes could be victimised. Therefore, both racism and sexism open up the possibility that "whites and men could be victims" (Wickberg, 2000), regardless of their non-oppressed state in society, and without specificity, the terms hindered the rhetoric behind the sociopolitical movements. By coining 'homophobia' psychological connotations were flipped accusing psychiatric establishments that purveyed 'homosexuality' as a mental illness, to be themselves sick. Stemming from Gay Liberation and Lesbian Feminist movements, a freedom of sexual expression rhetoric entered mass public discussion of gay rights and established this as a societal ideology. As a result of this activism, in December 1973 the American Psychiatric Association (APA) "voted unanimously that homosexuality should no longer be listed as a 'mental disorder"' in the Diagnostic and Statistical Manual of Mental Health Disorders (DSM) (Gramick, 1983), which provided a liberating time for gay rights advocates.

However, the 1980's didn't produce nearly as much progression for gay activists. In the context of Margaret Thatcher and Ronald Reagan a 'family values' rhetoric supplemented heightening economic anxieties which targeted gay and lesbian people and single mothers as the catalysts of this issue (Adam, Duyvendak, and Krouwel, 1999). The AIDS epidemic was also a source of contention over family and sexuality with many people wrongly citing gay men as the only cause. This instance, along with the exacerbation of moralistic right wing politics, created a moral panic against homosexuality (McCormack, 2014).

Regardless of these oppressive politics the activity of gay liberation and lesbian feminist movements created discussion spaces throughout the 1980's and 1990's in many urban centres around the world (Adam, Duyvendak, and Krouwel, 1999). Along with the introduction of the internet in the mid 1990's a political discussion was enabled that crossed geographical and cultural borders, and importantly opened the discourse to lesbian and gay youth, voices that had previously gone unheard (Gray, 2009). The internet has been a catalyst in much political mobility for gay activists and with supplementing positive media representation, to be discussed, it has resulted in substantial changes in public thinking: In Britain only $29 \%$ of adults consider same-sex relationships wrong which has decreased from $46 \%$ in 2000 (Curtice and Ormston, 2012). 29\% is not ideal and 
obviously this still shows an ignorance within public thinking in Britain, however, it is a massive step in the right direction, very much catalysed by communication through the internet. As a result of this change in public thinking, there were repercussions within the legal sector in Britain: McCormack (2014) states that "homophobic perspectives are no longer enshrined in English law", highlighting equal age of consent for same-sex sex and legalisation of gay marriage (133).

\section{Transgender Rights Politics}

From the recognition of, what we now label, transgender in the early twentieth century, individuals that fit into the category were pathologised and determined mentally ill (Lee, 2012). It was this immediate pathologisation and the rhetoric behind it that controlled (and still does) individuals that felt any deviation from the sex they were assigned at birth. Any individual that sought out sex reassignment surgery had to embody 'symptoms' of Gender Identity Disorder (GID), now called Gender Dysphoria (GD), manifesting in The Transexual Phenomenon (Benjamin et al., 1966); hence, pathologising themselves. By embodying symptoms, of what we now perceive as wrong body discourse (WBD), whether or not it is how transgender individuals interpreted their experience, they deceived doctors into providing them with the relevant treatments and eventually sex re-assignment surgery (Barker-Plummer, 2013). This can be understood as derivative of what Foucault (1978) highlighted as 'a psychiatrization of perverse pleasure' (105) that was occurring between 1700 and the victorian era, in which any subject whom didn't conform to 'procreative'sexuality was considered mentally ill. This is also one of the more recent examples of 'normalisation or pathologisation'. WBD fails to account for the heterogeneity of the whole transgender community, while it may justify transgender identities that are dysphoric, it does not account for individuals whose gender deviance is intentionally resistant or who fall onto the gender fluid spectrum away from the regimented binary (Barker-Plummer, 2013). WBD praises reinforcement of essentialist gender regulation rather than critiquing them, something that gender fluid activism rejects and endeavours to break down (Davis, 2009). To stop transphobic rhetoric, stemming from gender regulation, from circulating society, mass public discussions need to be achieved challenging cis- 
normative and heteronormative regimes that define society's views on gender and sexuality.

Pre-1990's transgender individuals taking a medical discourse were told by doctors to avoid other transgender people, in the hope that it would 'cure' their dysphoria and they would blend into society by 'passing' as their newly assumed gender, a perfect example of social normalisation in the context of gender regulation. As a result of this rhetoric many transgender individuals didn't seek out transgender communities. However, at the birth of the internet online news groups and email forums became popular for transgender people,creating a growing activist base, a 'new haven' for these identities much like 50's urbanisation for gay communities. It enabled gender deviating communities to dialogue their subjectivity of their experience which culminated in the formation of a new self identification category 'transgender' (Whittle, 1998); a liberating development, much like the construction of 'gay' and 'lesbian'.

Internet communities like these mobilised advocates to introduce transgender dialogue into public spaces, and eventually resulted in the Gender Recognition Act 2004 which legally recognised individuals' perceived gender providing it was male or female. Without internet communities catalysing mobilisation, these dialogues may not have entered the political circle for years. However good it may be that trans rights were progressing it still accentuated essentialist notions of gender into the mindset of the public; whilst positive on the surface, it still regimented this social normalisation of gender.

Retrospectively, unless authoritarian politics once again became popularised causing world wide conflicts or a mass health epidemic arose related to transgender, provided there is active political contribution, transgender advocates should stay positive that transgender rights (in some form) will continue to improve. However, considering the heterogeneity of the trans community it is in their interest to continue dialoguing gender fluid rhetorics through public discussion to deconstruct WBD and warrant GD's removal from the DSM. With interest in Gay Rights activism, it was the nuanced discussions about sexual expression in growing advocated groups, i.e. Lesbian Feminism and Gay Liberation, that pushed their dialogues into the public space. Public discussion was of course what authorised the removal of 'homosexuality' from the DSM in the 1970's, and the depathologisation of transgender would have huge liberatory effects for gender non- 
conforming individuals, much the same as homosexuality (Ault and Brzuzy, 2009). So, in order to gain a more powerful public discussion, specifically dialoguing gender fluidity through the use of Butler's ideas, transgender advocates must find a platform, with this specificity, to develop and enhance their growing rhetorics behind gender fluidity. In the following section this paper will outline the importance of popular media to continue mass public discussion of social minority narratives; the progression of gay representation and how it affected their political status; and the current state of transgender representation.

\section{The Importance and Downfall of Popular Media on Social Minorities}

Mainstream media presents to its viewers an image of the 'real social world', which many take as fact, when conversely it has simplified many identities that actually exist there. A simplification that has led to the stereotyping of many identities which has resulted in an invisibility of many identities within social groups. This relative invisibility has been termed as "symbolic annihilation", and the simplified representation of such identities reflects the interests of the elite: prominently white, middle class, heterosexual males (Gross, 1994) (143). The influence of the media, when used in this way, reinforces detrimental social definitions, and contrarily it could just as easily challenge existing regimented ideas of sexuality and gender (Capuzza and Spencer, 2016).

Obviously, then, for activists mainstream film and television representation are imperative in order to discuss transgender subjectivities on a mass public level. This is especially crucial for young transgender individuals as films and television with non- heteronormative sexual and gender narratives often act as their first comparative analysis of their own manifestations of sex and gender (Padva, 2007). Clark (1969) posited four sequential stages of media representation of social minority groups: non-recognition, ridicule, regulation, and respect. Through this section gay representation will be outlined chronologically in relation to Clark's hypothesis, and comparatively analysed with current transgender representation; and further how growing gender fluid politics would impact this discourse.

Although there have been gay-coded 'sissy' characters appearing since the earliest days 
of cinema, it was simply their gender transitive representation that compelled a nonstraight reading. They were always in minor supporting roles and there was never any progression of these characters to be coded in relation to sexuality, they simply remained 'laughable' because of their gender transitivity. Until the late 1960's gay representation remained in the non-recognition stage, where little to no narratives based around homosexuality existed in mainstream media. The Homosexuals (Wallace, 1967), a documentary on $\mathrm{CBS}$, brought gay representation into the ridicule stage, in which it framed characters under psychiatric contexts and provided a simplified and stereotyped summary of homosexuality (Hart, 2000). During this stage many television executives averted to gay narratives or anything linked to condoning homosexuality under the pretence that it would alienate viewers and advertisers (Alwood, 1996). Gay media representation progressed away from the ridicule stage in the 1970's due to the activism of the Gay liberation movement which increased visibility of gay identities in differing social positions all over the US (Hart, 2000). As a result gay men arrived in the regulation stage which emphasised gay characters in note-worthy, respectable professions illustrated in Barney Miller (Arnold and Flicker, 1975), in which 'Officer Zatelli' has a 'coming out' storyline in season 4 (1977).

Undoubtably, the AIDS epidemic had damaging consequences for gay media representation and progression halted until changing political rhetorics (Reagan/Bush to Bill Clinton) actively brought forward social tolerance for gay identified individuals (McKinney and Pepper, 1999). For mainstream networks, this change in public thinking became reason to capitalise on growing gay representation which pushed them into the respect stage in the 1990's. Series' like thirty-something (Herskovitz and Zwick, 1987), One Life to Live (Nixon, 1968), All My Children (Nixon, 1970), Ellen (Black, Marlens and Rosenthal, 1994), and Will \& Grace (Kohan and Mutchnick, 1998) all introduced diverse embodiments of gay characters in varied roles within American society (Hart, 2000). It has been a similar pattern in the progression of transgender representation which lingered in non-recognition until the 1990's. Silence of the Lambs (Demme, 1991) emphatically delivered transgender to mainstream audiences with Buffalo Bill, a deranged serial killer, which reinforced 'transgender' as pathologised. Booth (2011) states: "As is the case with any marginalized group, however, visibility is a risky prospect [...] an increase in media representation may be just as likely to further confuse the issue as to clarify it, 
particularly when the commercial interests controlling those representations are inclined to frame them in sensationalistic terms" (191).

During the 1990's transgender embodiment was used as a sensationalist device exemplified in The Crying Game (Jordan, 1992) and Ace Ventura: Pet Detective (Shadyac, 1994), with simplified representation: almost all white and prominently regimented to the gender binary. As Booth suggests, this visibility did nothing to challenge transphobia or open up the discussion about differing trans subjectivities, highlighting a symbolic annihilation of transgender. Presently, considering transgender representation, one could argue that it has entered the regulation stage with mainstream films like Transamerica (Tucker, 2005) and The Danish Girl (Hooper, 2015) starring strong transgender characters in respectable social positions. However, these narratives discourse essentialist notions of gender, specifically focus on transition and transgender characters are exclusively white (Fink and Miller, 2014); in this respect it might be more appropriate to label transsexual representation in the regulation stage. After realising the heterogeneity of the transgender population and searching for gender fluid representation in the media, one could argue that it may still be in the ridicule stage, exemplified by Piers Morgan's excessive derogatory rants about gender non-conforming pro-nouns. More recently, however, Channel 4's new commentary on gender transgression, Genderquake: The Debate (Coleman, 2018), perfectly exemplifies the public's ignorant attitude towards gender nonconformity as many of the audience were shouting transphobic abuse at the nonbinary members of the panel. The non-recognition/ridicule of gender fluidity was also evident on this panel, as the self recognised gender fluid character remained mostly outside of the discussion, with the majority of questions being aimed at the traditionally 'passing' transgender characters.

For the progression of gay representation in the media, it was growing public discussion of the societal positions upheld by a diverse collection of gay individuals that gay rights activism channeled. Perhaps, gender fluid activists should learn from this and continue to discourse the differing subjectivities of the transgender experience that is not solely based around transition. Following nuanced public discussion of the transgender experience one can expect a progression in media representation. Currently, the prominent tropes in 
media representation of transgender are all due to an essentialist understanding of gender. The minimal narratives in widespread circulation that contain transgender protagonists focus solely on transition, with their protagonists pathologised. In supporting roles they are often used as a sensationalist device to shock the viewer and at no point challenge essentialism whatsoever.

\section{Transgender Cyber Communities, Tumblr, and Trans* Activism}

Cyber communities can be defined as social clusters that appear on the internet when enough advocated individuals continue public discussion long enough to form interconnected personal relationships (Rheingold, 2000). Whittle (1998) suggests: "Cyberspace has presented a safe area where body image and presentation are not among the initial aspects of personal judgement and social hierarchy within the transgender community" (400). These communities have provided a space to share and learn about gender non- conforming individuals' unique health contexts, which is imperative for transgender youth to understand when considering their own gender development (Giesking and Hawkins, 2017). Importantly, it can also act as a space to discuss transgender politics. As online communities don't require any geographical proximity it is vitally important for transgender activists that they are used for social justice organising and discussion of international politics (Báez, 2013; Whittle, 1998). In sociopolitical context, cyber communities could certainly be understood as Transnational Advocacy Networks (TANs), large international groups that advocate change, which Ciszek (2017) claims have had considerable influence on public policy. An example of strategic communication is 'public relations', which is used to integrate organisations' political discourse into wider circles (Hallahan, Holtzhausen, van Ruler, Sriramesh, and Veri, 2007). Edwards (2012) defines 'public relations' as: "the flow of purposive communication produced on behalf of individuals, formally constituted and informally constituted groups, through their continuous transactions with other social entities. It has social, cultural, political, and economic effects at local, national and global levels" (21).

Access to resource is considered most important for advocates' ability to impart strategic 
communication on larger circles (Tarrow, 1994); this essay argues that online communities, within a public space, like YouTube and Tumblr are easily accessed by large populations worldwide and can be used to exert influence for social change.

Raun (2012) argues that transgender experience vlogs on YouTube act as online global activism, challenging the image of transsexuals as pathologised subjects. Through users cross referencing vlogs, coherent transgender narratives are created that are heard on a larger scale, which is an example of public relations. YouTube certainly has more diverse transgender representation than that of mainstream media, however, popular trans vloggers express normalised gender identity resultant from gender policing in comments sections, which exemplifies social normalisation of gender in action. These operationalised ideas of normality are explicit in users exhibiting gender policing rhetoric on YouTube and this process represses other gender variant users of the site. This has resulted in genderqueer trans-representation being minimal on the site, something that Tumblr seems to be superior in.

In 2012 Tumblr featured an editorial outlining the growing number of transgender youth on the site, with over $40 \%$ of all users aged between 15-24 (comScore, 2013). Drager (2012), a trans-masculine identified academic and Tumblr user, claims the site is perfect for trans youth hoping to find a personal and subjective community of gender non- conforming individuals. The platform works through multimedia posting and reposting that welcomes creativity and allows diverse transgender narratives to be engaged with through a range of media. Tumblr stands out in comparison to other social networking sites like YouTube, accommodating gender policing; and Facebook which has caused embarrassment and ridicule for transitioning individuals with bugs revealing their previous gender (Haimson and Hayes, 2014). Much like YouTube vlogs cross-referencing videos, Tumblr posts create coherent and diverse transgender narratives with their 'notes' system. The original postee may add a 'note' to a post much like a description; users may then re-blog this post and add their own commentary (note) to it; and this commentary can continue with 'notes' chaining for as long as necessary. However, in contrast to YouTube and Facebook comment systems, re- blogging is necessary to add your own note; meaning that unhelpful, derogatory, and ideologically conflicting comments do not reach as many users. Further, when users with influence (many followers) add commentary it opens the 
discussion into wider public spaces. The advancement of Tumblr dialogues, away from the gender policed spheres of YouTube and Facebook, is the perfect example of why it could be a great platform to open up a wider discussion about transgender, one that challenges the current operationalised ideas of normality that exist in western civilisation (Foucault, 1977).

However, contentious tagging has been a key issue in relation to transgender discourse on Tumblr's platform. Unfortunately, being accessible to corporate accounts generating automated posts regularly, it has led to the fetishisation of \#transgender: much of the content related to the tag being explicit fetish pornography. This fetishisation has forced transgender users to find new tags, like \#trans ${ }^{*}$, to represent their community, which is known as a 'folksonomy': "the result of personal free tagging of information and objects (anything with a URL) for one's own retrieval," used in "a social environment", that creates context "derived from people using their own vocabulary and adding explicit meaning" (Vander Wal, 2005). The folksonomy of \#trans* has meant that it has distanced transgender discourse from the more public \#transgender space, limiting its visibility and political impact on larger audiences on Tumblr (Dame, 2016). Because of this folksonomy hiding the activist commentary, that is found under the tag \#trans*, the message that users are trying to exhibit is restricted. Presently, it is only being engaged by a smaller number of already advocated individuals, instead of opening up the discussion to wider public spaces that is imperative to create momentum within this social justice organising. It is online communities like trans ${ }^{*}$ that are central to gaining understanding of gender identity and political consciousness, the heterogeneity of such groups are a complete contrast to dominant images of queer identities in mainstream media (Drager, 2012). This group acts as a manifestation of an argument Butler (1990) raised: "When the constructed status of gender is theorised as radically independent of sex, gender itself becomes a free floating artifice, with the consequence that man and masculine might just as easily signify a female body as a male one, and woman and feminine a male body a easily as a female one" (6).

It is the heterogeneity of gender transgression exemplified in mass within groups like this, that challenges the operationalised ideas of normality that currently exist; and further, it displays gender transgression as a social ideology that should be recognised in the field of 
psychology that being transgender is not a mental illness. The rhetoric of 'transition' is changing: some bloggers choose to stay identified as 'in transition' after completing surgeries; and some choose not to enter a medical discourse whatsoever and focus on natural ways of achieving a different body shape or internal chemistry (Drager, 2012). This type of transgression from normative transition narratives exemplifies the complexity and diversity of transgender subjectivities, deconstructing WBD, which highlights the need to propagate gender fluid rhetoric into the public arena. Trans* youth communities are developing anti-assimilationist and anti- passing rhetorics in respect to trans ${ }^{*}$ liberation, all dialogued through notes on Tumblr (Drager, 2012). This puts pressure onto 'social normalisation' rhetorics assumed under assimilationist politics that the mainstream queer movement uphold; and further presents an expansive and inclusive re-imagination of queer politics. By dialoguing these ideas and identities in a more public space, progressing away from from the folksonomy of \#trans*, one could see, already coherent, narratives that exemplify gender fluidity and challenge operationalised ideas of normality within the public sphere. This would create a larger visibility of gender fluid commentary that progressive minded filmmakers could capitalise on, and convince larger studios to create, much needed, gender fluid narratives that would help transgender rights movement climb from 'ridicule' into the 'respect' stage quicker.

Unlike \#LGBTQ, \#transgender is not a 'featured' tag on Tumblr, so does not have the benefits of editors and 'top contributors'. If Tumblr was to make \#transgender a featured tag it could police the fetishised pornography; create a public space for strategic communication of trans ${ }^{*}$ specific arguments; and influence wider circles with commentary from 'top contributors'. Considering that Tumblr is one of largest online transgender youth communities, welcoming such heterogeneity, it is imperative that Tumblr becomes active in supporting transgender sociopolitical action. As a critique of Tumblr's platform it is evident that, with the changes proposed, it could have the power to make a substantial difference in what transgender activism looks like - an inclusive, gender fluid, antiassimilationist movement that evidences a rejection of the current media tropes of transgender representation. A progression away from essentialist gender narratives, like Transamerica (Tucker, 2005) and The Danish Girl (Hooper, 2015), is needed that rejects the idea of 'normalisation or pathologisation' (Foucault) and comments on anti-passing 
rhetorics that are now circulating online communities. A progression into narratives that transgress essentialist notions of gender would give a huge momentum for the transgender rights movement; bring a much larger visibility to the wider/global public; and with further advocated discussion, it would eventually lead to a public realisation that gender fluidity is a 'normative ideology' warranting, for psychologists, the removal of Gender Dysphoria (GD) from the DSM.

\section{Conclusion}

The internet has been overwhelmingly important in the mobilisation of social minorities. Specifically, with the growth of social networking, it has been a place that minority youth can contribute. As a result, Tumblr has become one of the largest online communities of transgender youth subjects. By featuring \#transgender, Tumblr can become an active force at the base of gender fluid politics, creating a space for strategic communication for further trans* discourse. Firstly by accessing LGBTQ+ youth circles it could see an expansive and inclusive re-imagination in the rhetoric of queer politics, centring antiassimilationist and anti-passing politics at its core, hence fighting obsolete operationalised ideas of what is 'normal', and putting a stop to social normalisation of gender. A larger mobilisation of these politics, transversing social-networks, into mainstream media, tackling its current essentialist mindset, would bring gender fluid identities from nonrecognition to the respect stage very quickly. Mainstream media has the potential to become one of the most influential advocates of gender fluid rhetoric which would be influential in deconstructing WBD and essentialist ideas of gender, and furthermore challenge psychiatric definitions upheld in the DSM, warranting its removal. The depathologisation of transgender would have incredible liberatory effects to the transgender population much like gay liberation in the 1970's. At its base, by simply featuring \#transgender on Tumblr, one of the largest online communities of gender fluid identities would have the chance to spark a movement that is capable of achieving this feat. 


\section{References}

Adam, B., Duyvendak, J. and Krouwel, A. (1999). Introduction. In: B. Adam, J. Duyvendak and A. Krouwel, ed., Global Emergence Of Gay \& Lesbian Politics: National Imprints of a Worldwide Movement, 1st ed. Philadelphia: Temple University Press, pp.1-9.

Alwood, E. (1996). Straight news: Gays, lesbians, and the news media. New York: Columbia University Press.

Ault, A. and Brzuzy, S. (2009). Removing Gender Identity Disorder from the "Diagnostic and Statistical Manual of Mental Disorders": A Call for Action. Social Work, 54(2), pp. 187-189.

Báez, J. (2013). Structurelessness 2.0. WSQ: Women's Studies Quarterly, 41(3), 253-256. Barker-Plummer, B. (2013). Fixing Gwen. Feminist Media Studies, 13(4), pp.710-724.

Benjamin, H., Lal, G., Green, R. and Masters, R. (1966). The Transsexual Phenomenon. 1st ed. New York, N.Y.: Ace Pub. Co.

Benshoff, H. and Griffin, S. (2006). Queer images. Lanham, Md.: Rowman \& Littlefield Pub.

Booth, E. (2011). QueeringQueer Eye: The Stability of Gay Identity Confronts the Liminality of Trans Embodiment. Western Journal of Communication, 75(2), pp.185-204.

Butler, J. (1990). Gender trouble. Routledge.

Clark, C. (1969). Television and social controls: Some observation of the portrayal of ethnic minorities. Television Quarterly, 9(2), 18-22.

comScore. (2013). Will Tumblr bring a younger audience to Yahoo! sites?. [online] Available at: http://www.comscoredatamine.com/2013/05/will-tumblr-bring-a-youngeraudience-toyahoo-sites/ [Accessed 20 Dec. 2017].

Ciszek, E. (2017). Activist Strategic Communication for Social Change: A Transnational Case Study of Lesbian, Gay, Bisexual, and Transgender Activism. Journal of Communication, 67, pp.702-718.

Curtice, J. and Ormston, R. (2012). Devolu-tion. British Social Attitudes Survey, London: NatCen Social Research.

Dame, A. (2016). Making a name for yourself: tagging as transgender ontological practice on Tumblr. Critical Studies in Media Communication, 33(1), pp. 23-37.

Davis, E. (2009). Situating "Fluidity": (Trans) Gender Identification and the Regulation of Gender Diversity. GLQ: A Journal of Lesbian and Gay Studies, 15(1), pp.97-130. 
Drager, H. (2012). Transforming Cyber Space and the Trans Liberation Movement: A study of transmasculine youth bloggers on Tumblr.com. Undergraduate. University of Colorado.

Epstein, S. (1999). Gay and Lesbian Movements in the United States: Dilemmas of Identity, Diversity, and Political Strategy. In: B. Adam, J. Duyvendak and A. Krouwel, ed., Global Emergence Of Gay \& Lesbian Politics: National Imprints of a Worldwide Movement, 1st ed. Philadelphia: Temple University Press, pp. 30 - 34.

Fink, M. and Miller, Q. (2014). Trans Media Moments: Tumblr, 2011-2013. Television \& New Media, 15(7), 611-626.

Foucault, M. (1977). Discipline and punish. New York: Pantheon Books.

Foucault, M. (1978). The History of Sexuality, Volume 1: An Introduction. New York: Pantheon Books.

Giesking, J. and Hawkins, B. (2017). Seeking ways to our transgender bodies, by ourselves: Rationalizing transgender-specific health information behaviors. Proceedings of the Association for Information Science and Technology, 54(1), pp.702-704.

Gramick, J. (1983). Homophobia: A New Challenge. Social Work, 28, pp. 137-141. Gray, M.L. (2009). Out in the Country. New York: New York University Press.

Gross, L. (1994). What is wrong with this picture? Lesbian women and gay men on television. In: R.J. Ringer, ed., Queer words, queer images: Communication and the construction of homosexuality. New York: New York University Press, pp. 143-156.

Haimson, O. and Hayes, G. (2014). Understanding Gender Transition on Social Media to Design Technology for Changing Identities. [online] Available at: http://oliverhaimson.com/ PDFs/HaimsonUnderstandingGenderTransition.pdf [Accessed 23 Dec. 2017].

Hallahan, K., Holtzhausen, D., van Ruler, B., Sriramesh, K. and Veri, D. (2007). Defining strategic communication. International Journal of Strategic Communication, 1, pp. 3-35.

Hart, K.R. (2000). Representing Gay Men on American Television. The Journal of Men's Studies, 9(1), pp. 59-79.

Hines, S. (2006). What's the Difference? Bringing Particularity to Queer Studies of Transgender. Journal of Gender Studies, 15(1), pp.49.

Joey and Kaiden. (2011). What does the asterisk after the word 'trans' mean?. You Know You're Trans When. [Tumblr post].

Lee, M. (2012). The Paradox of Authenticity: The Depoliticization of Trans Identity. Master of the Arts. Ohio State University, pp.12-22.

McCormack, M. (2014). The Intersection of Youth Masculinities, Decreasing Homophobia 
and Class: An Ethnography. The British Journal of Sociology, 65(1), pp. 130-150.

McKinney, M.S. and Pepper, B.G. (1999). From hope to heartbreak: Bill Clinton and the rhetoric of AIDS. In: W.N. Elwood, ed., Power in the blood: A handbook on AIDS, politics, and communication, Mahwah, NJ: Lawrence Erlbaum Associates, pp. 77-92.

Padva, G. (2007). Media and Popular Culture Representations of LGBT Bullying. Journal of Gay \& Lesbian Social Services, 19(3-4), pp.105-118.

Raun, T. (2012). Out Online: Trans Self Representation and Community Building on YouTube. PhD. Roskilde University.

Richardson, N. (2010). Transgressive Bodies: Representations in film and popular culture. 1st ed. Routledge, pp. 121-129.

Rheingold, H. (2000) The Virtual Community: Homesteading on the Electronic Frontier, Cambridge, MA: MIT Press.

Tarrow, S. (1994). Power in movement: Social movements, collective action and mass politics. Cambridge, England: Cambridge University Press.

Vander Wal, T. (2005). Folksonomy definition and Wikipedia. [online] Available at: http:// www.vanderwal.net/random/entrysel.php?blog=1750 [Accessed 2 Jan. 2018].

Wallerstein, I. (1989). 1968, Revolution in the World System. Theory and Society, 18(1), pp. 431-449.

Weinberg, G. (1972). Society and the Healthy Homosexual. New York: St. Martin's Press.

Whittle, S. (1998). The Trans-Cyberian Mail Way. Social \& Legal Studies, 7(3), pp.389408.

Wickberg, D. (2000). Homophobia: On the Cultural History of an Idea. Critical Inquiry, 27(1), pp. 42-57.

\section{TV and Film's Cited}

Ace Ventura: Pet Detective. (1994). [Film] Directed by T. Shadyac.

All My Children. (1970). [TV] Created by A. Nixon.

Barney Miller. (1975). [TV] Created by D. Arnold. and T.J. Flicker.

CBS Reports: The Homosexuals. (1967). [TV] Presented by M. Wallace.

Ellen. (1994). [TV] Created by C. Black., N. Marlens. and D.S. Rosenthal. 
Genderquake: The Debate. (2018). [TV] Directed by D. Coleman.

One Life to Live. (1968). [TV] Created by A. Nixon.

Silence of the Lambs. (1991). [Film] Directed by J. Demme.

The Crying Game. (1992). [Film] Directed by N. Jordan.

The Danish Girl. (2015). [Film] Directed by T. Hooper.

thirtysomething. (1987). [TV] Created by M. Herskovitz. and E. Zwick.

Transamerica. (2005). [Film] Directed by D. Tucker.

Will \& Grace. (1998). [TV] Created by D. Kohen. and M. Mutchnick. 